\title{
O Corpo da Poesia. Notas para uma fenomenologia da poesia, segundo Orides Fontela
}

Haquira Osakabe

Poucos são aqueles que se conformam com o que a linguagem do seu dia-a-dia lhes coloca à disposição. Sobretudo se forem poetas. Parece haver nestes sempre uma inquietação, algo que os convoca não só ao travo de uma constante insatisfação, mas também a uma contínua luta pela superação daquilo que lhes parece ser limite de seu próprio instrumento de invenção. A banalidade dessa constatação esconde, na verdade, algo que vai muito além daquele lugar-comum segundo o qual os poetas são sempre seres insatisfeitos.

Lembremos que Mallarmé, ao referir-se a uma arte descritiva como a parnasiana, teria dito que o segredo da arte, ou da poesia era sugerir ao invés de nomear. ${ }^{1}$ Uma primeira decorrência dessa formulação do grande poeta é a de que, em poesia, só se diz algo sugerindo, ou que algo só encontra sua expressão num modo indireto de referenciamento (a alusão, nos termos do próprio Mallarmé). Em outros termos, a experiência poética ou o ato de poetizar um objeto só é formulável por via da sugestão, ou se preferirmos, por um modo alusivo e não afirmativo de dizer. Uma decorrência desse pensamento de Mallarmé vem a ser a de que não há como dizer a coisa poética, ou melhor, de que a linguagem usual, aquela que se apresenta ao poeta no seu dia-a-dia, é incapaz de captar e formalizar o fato poético. O sujeito para tentar fazê-lo teria de apelar para uma espécie de jogo ou de invenção que lhe permitiria superar a distância entre os dois pólos: a experiência do suposto objeto e sua formulação. No entanto, há algo que soa estranho nesse modo de entender o pensamento de Mallarmé e que merece uma melhor discussão. Trata-se do pressuposto de uma distância entre a experiência da apreen- 
são do objeto poético e a linguagem que o expressaria. Na verdade, como se verá mais adiante, é impossível separar-se uma coisa de outra, já que entre experiência e sua formulação não se pode estabelecer uma relação de dependência nem causal nem temporal. A formulação da experiência é simultânea à sua ocorrência. E é ela, a formulação, que confere existência à experiência. ${ }^{2}$ Logo, a questão da indizibilidade desta, nesse sentido, parece ser uma falsa questão. Ou diz-se a experiência ou esta simplesmente não existe. $\mathrm{O}$ que está em foco é o fato de que a poesia exige do seu sujeito uma atitude de linguagem muito particular e, desse modo, uma experiência também muito particular. Cabe interrogar um pouco mais sobre isso.

O fato de ter-me referido a Mallarmé para iniciar a presente discussão não é gratuito; seu nome está ligado à grande alteração que em matéria de linguagem se deu na literatura ocidental na segunda metade do século XIX e que está na base de quase todas as grandes questões estéticas pelas quais passou a literatura do próprio século XX. Na raiz dessa alteração, quaisquer que tenham sido suas decorrências, está o pressuposto da predominância da função de representação da poesia para a de constituição. Explicitemos isso: até o período precedente, correspondente grosso modo ao romantismo-realismo, persistia a convicção de que a poesia necessariamente seria resultado de um processo em que se traduziria não apenas um estado de alma mas uma realidade racionalmente referenciável. Isto porque ela estaria ajustada a formas de representação já definidas. O que está subjacente aí é a persistência da exigência clássica da clareza ou da fidedignidade da poesia e com isso a convicção de que a linguagem, nesse caso poética, alcança formular em perfeição o seu objeto. A persistência dessa convicção pode muito bem ser avaliada nas discussões suscitadas pela poesia barroca, cujo modo de elaboração presumivelmente teria implicado uma transgressão ao princípio da clareza. ${ }^{3}$

$\mathrm{Na}$ verdade, o que ocorre com a poesia no século XIX, e que tem relação muito forte com o que se tem chamado de irrupção do irraciona- 
lismo no pensamento ocidental, remete a um processo de surpreendente deslocamento de perspectiva que sobretudo Schopenhauer verbalizou de modo claríssimo. Lembremos aqui a radical inversão proposta por ele em sua filosofia quando postula, na distinção entre aparência e coisa em si, o caráter de Representação, racionalmente formulável, da primeira e a natureza irracional e incontrolável da segunda e que corresponderia ao que chamou de Vontade. ${ }^{4}$ Esta seria a força cega que, em contínuo movimento, propulsionaria o universo em todas as suas instâncias. Impossível de ser captada racionalmente, apenas a arte, e mais particularmente as artes não representativas, como a poesia trágica ou a música, poderiam permitir ao homem aproximar-se dela. Ou aproximar-se daquilo que seria o em si da coisa. As razões dessa alteração de perspectiva que encontra seus nomes mais expressivos em Baudelaire, Rimbaud, Mallarmé, na poesia, ou um Wagner na música, são assunto para uma outra ocasião. Nesse contexto e tendo em vista que a poesia em última instância visa aproximar o seu sujeito dessa coisa em si, é que se pode entender a atitude dos primeiros simbolistas quando se referiam ao inefável como objeto de sua poesia. A indizibilidade essencial desse objeto, ou a impossibilidade de enformá-lo dentro da linguagem declarativa, é que daria razão a Mallarmé na idéia, acima referida, de que a poesia tem de deixar de representar (ou seja nomear) para aludir ou sugerir. Porém sugerir não mais o preexistente ou racionalizável, mas a própria experiência de aproximação entre o sujeito e o objeto. E nisso talvez eu tenha de precisar como venho interpretando o pensamento de Mallarmé, entendendo que o sugerir, ativando outras vias de conhecimento além da razão, não constitui uma atividade do sujeito na reconstrução de um objeto, mas sim, na formulação da experiência do objeto pelo sujeito. O caráter radicalmente subjetivo dessa experiência, e sua natureza não racional, determinaria não apenas a aproximação do sujeito com o em si (ou a essência) da coisa, mas também a aproximação do em si do sujeito com o em si da coisa. Nesse sentido, a poesia, muito menos que representação, seria o próprio fluxo que resultaria dessa aproximação. É esse ponto que interessa desenvolver aqui. 
Uma via que me parece bastante esclarecedora para começar a explorar a questão posta nesses termos é situá-la no interior de alguns dos lugares teóricos mais assentes na ciência lingüística durante o século XX. Acusada de estar baseada num forte reducionismo racionalista, a lingüística logrou traçar de modo incisivo um recorte sobre o fenômeno da linguagem que lhe permitiu "isolar" estrategicamente o objeto científico de sua variação fenomênica. ${ }^{5}$ Lingua nos termos saussurianos ou competência em termos de uma gramática gerativa, o certo é que esse recorte obedece a parâmetros inversos àqueles definidos por Schopenhauer. A lingua ou a competência reúnem o conjunto de invariantes cujo modo de organização obedece a princípios formalizáveis. Têm nesse sentido uma natureza estável, para não dizer fixa, alheia ao movimento que tempo e situações inevitavelmente provocam. Nos termos de Schopenhauer estaria no plano da Representação e não da Vontade. A clara opção da ciência por essa redução não deve ser considerada apenas como resultante de uma percepção asséptica da linguagem de onde se estirparia o que seria supérfluo, mas também como resultado de uma aceitação de que os instrumentos da razão, diante da complexidade da linguagem, são limitados. De qualquer modo, retomando aqui as questões levantadas pelos simbolistas, estamos, dentro da ciência lingüística, muito longe do chamado inefável, e aquilo de que ela dá conta fica a milhões de anos-luz da possiblidade de constituição do objeto poético tal como Mallarmé o preconizava. Isto é, não se constrói poesia com a razão lingüística.

G.G. Granger em sua Filosofia do Estilo ${ }^{6}$ afirma que todo processo lingüístico (sobretudo o metalingüístico) é redutor e que toda manifestação lingüística tende sempre a deixar de fora algo que os instrumentos gerais da língua não dariam conta de formular. Seriam os resíduos, na sua terminologia. A noção de estilo entraria aí, como resultante de um esforço particular do sujeito na manipulação de recursos lingüísticos capazes de reduzir o peso do resíduo, ou a distância entre o dito e a experiência, esta podendo ser entendida como resultante de um contato de todas as faculdades do sujeito com o mundo objetivo. Nos termos da 
discussão dos simbolistas feita anteriormente, poder-se-ia pensar que todo poeta privilegiaria essa faixa que a linguagem objetiva deixaria de fora, tentando formular lingüisticamente o lado informulável da experiência.

As observações de Granger abrem uma via esclarecedora para uma reflexão sobre a questão, não pelo que afirma, mas sim pela brecha que sua análise deixa exposta. Parece que, na formulação do filósofo, o sujeito e sobretudo o poeta têm de enfrentar com a invenção permanente do estilo uma atividade que é sempre da ordem da exceção da linguagem $e$ não da sua essência. O que, em outros termos, ratifica o tradicional entendimento da poesia como resultante de um desvio, isto é, como atividade complementar que resulta de um esforço individual no sentido de suprir uma falta essencial da linguagem. Como se, pela natureza de seu instrumento, sobrasse ao poeta a inevitável sensação de estar fora do mundo "normal", deslocado dele como um equívoco.

Este é o ponto nuclear do presente ensaio, e sua discussão exige uma espécie de confronto entre o ponto de vista da ciência e também da tradição retórico-poética de cariz racionalista e o do poeta, tal como ele pode ser situado aqui na tradição mallarmaica. Além disso, esse ponto parece convocar inapelavelmente a questão do poder revelador da poesia, o que, em última instância, exige que se considere sempre a questão de sua relação com um conhecimento que lhe seja particular ou próprio. Para entrar nessa discussão, vou invocar aqui alguns poemas de Orides Fontela que dentro da poesia brasileira me parece ter sido quem tocou de modo mais preciso a questão. Consideremos o poema "Rosa"

\footnotetext{
Eu assassinei o nome

da flor

e a mesma flor forma complexa

simplifiqui-a no simbolo

(mas sem elidir o sangue).
} 
Porém se unicamente

a palavra FLOR - a palavra

em si é bumanidade

como expressar mais o que

é densidade inverbal, viva?

(A ex-rosa, o crepúsculo

o borizonte.)

Eu assassinei a palavra

e tenho as mãos vivas em sangue $e^{7}$

O que significaria assassinar o nome da flor, simplificando-a no símbolo, sem elidir o sangue? Veja-se que o que está sendo posto em questão é a simples experiência de dizer a palavra "Rosa", com toda a carga vital que esse ato implica: a coisa sendo a palavra e a palavra incorporando indissociavelmente a coisa. $\mathrm{O}$ que teria ficado à margem nessa experiência de dizer, se nem o sangue fora elidido? A resposta se acha na segunda estrofe: o que ficou à margem é a densidade inverbal, viva. Logo, o que ficou de fora é aquilo que não se reduz, é pura densidade. Mas o que se capturou, ao se pronunciar a palavra rosa? Capturou-se o possível, aquilo que é da ordem do humano, aquilo que está ao alcance da palavra, instrumento que o homem se criou para inventar-se no próprio mundo. Mas por que falar então em assassinato, se dizere é da ordem do puramente humano? $\mathrm{O}$ assassinar o nome seria assim uma fatalidade humana? Em outros termos, dizer a palavra seria assassiná-la e fazê-la sangrar? Como não o fazer?

Essas questões permitem perceber que, do ponto de vista da autora, a palavra poética extrapola em muito a visão da linguagem como representação de algo que a antecede. Sim. A palavra poética é criadora de si mesma e a si mesma se consome porque, ao dizer-se, ela esvai-se na sua própria vitalidade. É condição de sua própria precariedade. A rosa 
que se pronuncia é sempre uma ex-rosa, finda, que vai, enquanto enunciada, morrendo-se já nesse mesmo ato.

Um outro poema de Orides Fontela diz

\author{
Fala \\ Tudo \\ será difícil de dizer: \\ a palavra real \\ nunca é suave.
}

Tudo será duro:

luz impiedosa

excessiva vivência

consciência demais do ser

Tudo será

capaz de ferir. Será

agressivamente real.

Tão real que nos despedaça.

Não há piedade nos signos

e nem no amor: o ser

é excessivamente lúcido

e a palavra é densa e nos fere.

(Toda palavra é crueldade.) ${ }^{8}$

Aqui a palavra real é dita nunca suave, daí a dificuldade de dizerer, porque neste ato se compreende a luminosidade impiedosa, a excessiva vivência do ser. É preciso ir-se um pouco além, nessa formulação que o poema nos dá: fala-se aí de uma palavra real, aquela que é ao mesmo tem- 
po consciência e vivência do ser. Estamos no âmago da linguagem, além das aparências. E a densidade de tudo isso, do que é real, fere-nos como sujeitos desse mesmo ato de enunciar a palavra.

Há uma relação especular entre esse poema e o antecedente: enquanto no primeiro o sujeito feria, ou assassinava a palavra ao dizê-la, neste outro é a palavra que, pela sua densidade, ou realidade excessiva, fere o próprio sujeito.

$\mathrm{Na}$ verdade é uma relação complementar em que ambos, sujeito e objeto, se indissociam, experienciando-se mutuamente, ferindo-se mutuamente com o próprio ato de dizer.

Há algo que pode parecer paradoxal nesses poemas de Orides. São eles cerebrais, tangenciando a abstração e, no entanto, há algo neles que leva para além de nossa razão, a regiões obscuras, pouco delineáveis. Qual a natureza da realidade/experiência que esses poemas permitem ao leitor vivenciar? Como ela nos chega? Via razão? Em parte. Mas sobretudo via sentidos: veja-se o impacto que produzem expressões nucleares como: assassinei a palavral e tenho as mãos vivas em sangue. Ou Não há piedade nos signos/ e nem no amor: o ser é excessivamente lúcido/ e a palavra é densa e nos fere. Para além dos limites de significação imediatamente apreensível, esses enunciados têm o dom de dizer (é a porta de entrada do mistério) e o dom de ocultar (serem portadores do irrevelável, de uma outra dimensão da significação), emanando de uma zona de difícil delineamento, para não dizer inteiramente opaca: por que assassinato? O que é o sangue da palavra? O que seria a piedade dos signos?

Mas é justamente essa duplicidade (via de acesso e bloqueio) que permite perceber a distância entre esses enunciados e aqueles claramente declarativos (se é que esses efetivamente ocorrem). Por conta disso, por se produzir como algo não redutivel (inverbal, nesse sentido), é que o contacto nosso com esse tipo de enunciado ultrapassa a esfera da informação intelectiva e impõe-se como uma experiência, no sentido que confere a essa palavra G.G. Granger, ao convocar, portanto, a totalidade de nossas faculdades para uma aproximação ao seu entendimento. Daí que 
sobra em nós o mesmo sentimento que gera a indagação de ambos os poemas: o sofrimento de capturar e perder ao mesmo tempo a coisa que se intui e não se formaliza; coisa que, uma vez formulada na sua própria precariedade, cola-se em nós definitivamente; e que, embora momentânea na sua ocorrência, pereniza-se nas marcas que imprime na nossa memória.

O que no leitor sobra dessa experiência da poesia é o outro em que ele se transforma, como resultado do rito sacrificial que o fazer poético denuncia (parodiando a própria poetisa, não há piedade na linguagem ou dizer é sempre um ato de assassinar). Fato absolutamente simples parece ser essa formulação: fora da rosa que eu digo não há outra rosa, e ao dizê-la, a palavra, coisa humana, me entrega a palavra e a coisa ao mesmo tempo, mas em fazendo-o, inevitavelmente estaremos matando, nesse mesmo ato, aquilo que os sentidos tangenciam e a razão não alcança. A singularidade da palavra é decorrência de sua própria precariedade. Sua riqueza e sua fragilidade ao mesmo tempo.

Quem é, portanto, o poeta? Um transgressor dos limites de seu próprio instrumento humano que é a palavra? Sim, se admitirmos que a natureza desta é da ordem do pragmático, da formulação do conhecimento objetivo, ou do poder determinante da Razão. Ocorre, no entanto, que a poesia, mesmo a mais cerebral, como é o caso da de Orides Fontela, realiza-se, tal como ela mesma diz, não por expressar algo que a antecede, mas sim, por ser esse algo na medida em que é enunciada. (Impossível não se remeter, nesse aspecto, à idéias de um Austin, estendendo talvez indevidamente o alcance de seu trabalho, alcance presumível no título francês de seu trabalho "Quand dire c'est faire".')

Vale a pena retomar aqui a noção de singularidade, acima referida. É um traço que caracteriza todo e qualquer ato particular de linguagem que, nesse sentido, é irreprodutível e intransferível (lembremos, a rosa nomeada é a ex-rosa). Mas paradoxalmente, nesse sentido é que ela, a palavra poética, se pereniza: por inscrever em si a marca de sua própria singularidade, ou o frescor da palavra sempre inaugural. ${ }^{10} \mathrm{~A}$ diferença da 
palavra usual, pragmática, com a palavra poética estaria aí. Daí que seja ela fluxo, fenômeno irredutível, revelando-se constantemente na sua novidade. Há qualquer coisa de extraordinário nisso: como algo que se pereniza pode ser ao mesmo tempo fluxo, mutabilidade, coisa nova, algo que se desfaz sempre que acontece? Aqui nos situamos na região menos devassável dessa questão: a poesia, não sendo uma construção declarativa, se reserva sempre uma região que nenhuma paráfrase pode reproduzir. Tal como ela mesma se constrói como alusão cobrindo com o mistério da palavra sugerida a essência de seu objeto, ela mesma se permite apenas ser alusiva a si própria e só se deixa aproximar pela via indireta da sugestão. Daí que não se esgote jamais. Daí que a cada vez que acontece de se apresentar para um mesmo leitor, ela o convoca para uma experiência nova, para uma nova singularidade. $\mathrm{E}$ por isso mesmo, provoca nele a mesma e renovada sensação de novidade e de descoberta. Orides Fontela nomeia esse poder vital da palavra poética "milagre de vida".

Voltemos agora ao confronto com a tradição racionalista de que a visão científica é o coroamento: a palavra, enquanto fluxo, é da ordem do fenômeno, carregando, portanto, uma série de variáveis não só de ordem subjetiva, mas de ordem situacional, contingencial.

Desse ponto de vista, a essência da linguagem, aquilo que seria invariável, remeteria a certos componentes (racionalmente sistematizáveis) que deixariam de fora tudo aquilo que é da ordem do fluxo. É justamente aqui que se pode invocar de novo um Schopenhauer e toda a tradição mallarmaica de concepção poética. Assim, como a "Vontade", a poesia é fluxo, mutabilidade, uma contínua novidade (e um impulso também cego, tanto que convoca todos os sentidos e não a intelecção racional). Tal como a "Vontade" Schopenhaueriana, ela não é o supérfluo nem o contingente, ela está no centro mesmo da linguagem. Logo, não é uma atividade marginal, da ordem da exceção. Ela é essencial à linguagem pois é o lugar onde esta se realiza, por excelência, já que aí ela se efetiva em seu grau máximo. Eu evocaria aqui o sonho da palavra 
translúcida de que foi portador o angustiado poeta Torquato Neto imaginando uma palavra tão transparente que nada lhe sombreie os limites. A palavra pura. Ora, a única palavra que se cumpre na sua translucidez é a palavra poética, fluxo puro que flui e não se controla, que é exatamente o que é: experiência que se dispõe perigosamente ao sujeito, ao convocálo para a consubstanciação única desse sonho, mas que se desfaz dramaticamente na sua própria precariedade. É a palavra providencialmente obscurecida pela sua própria impossibilidade. Por isso, um poema, fixado pela Razão, morre e mata em nós o sentido de sua própria novidade.

A poesia assim pensada corresponde à figura do pássaro que num magistral poema de Orides Fontela é assim aludido:

Elegia(I)

\section{Mas para que serve o pássaro}

Nós o contemplamos inerte.

Nós o tocamos no mágico fulgor das penas.

De que serve o pássaro se

desnaturado o possuimos?

O que era vồ e eis

que é concreção letal e cor

paralisada, iris silente, nitido,

o que era infinito e eis

que épeso e forma, verbo fixado, lúdico

O que era pássaro e é

o objeto: jogo

de uma inocência que

o contempla e revive

- criança que tateia 


\author{
no pássaro um esquema \\ de distâncias - \\ mas para que serve o pássaro? \\ O pássaro não serve. Arritmicas \\ brandas asas repousam. ${ }^{11}$
}

O poema todo tenta responder ao pragmatismo, ou ao imediatismo, contido na pergunta inicial: Mas para que serve o pássaro.? Na verdade, para que serve capturarmos o pássaro? Retido pelas nossas mãos, ele se desnatura, só peso e forma, e como a linguagem, o pássaro que possuímos, é verbo fixado. "O pássaro não serve", diz o poema no final, da mesma forma que a própria poesia não serve. Capturada, reduzida, o que era poema, torna-se objeto inerte. Tal como o pássaro aprisionado, o poema não serve, ele flui com asas arrítmicas, sua condição essencial é a fugacidade cujo núcleo só a própria palavra poética pode aceder.

Para pôr um fim provisório a esta exposição, remeto aqui ao poema Tempo, em que Orides Fontela diz:

\footnotetext{
O fluxo obriga

qualquer flor

a abrigar-se em si mesma

sem memória.

- Mas eis que a palavra

cantoflorvivência

re-nascendo perpétua

obriga ofluxo

cavalga o fluxo num milagre

de vida. ${ }^{12}$
} 


\section{Notas}

1 Nommer un objet, c'est suprimmer les trois-quarts de la jouissance du poème qui est faite de deviner peu à peu; le suggérer, voilà le rêve. Mallarmé, S. Oeuvres Complètes. Paris: Gallimard, 1945.

2 A questão da interdependência entre esses dois pólos mereceu do colega Carlos Franchi uma alentada discussão. V. "Linguagem como atividade constitutiva", in Almanaque 5. São Paulo: Ed. Brasiliense, 1977.

3 No mesmo texto de Mallarmé citado à nota 1, seu interlocutor, Jules Huret, apontalhe como objeção às suas idéias o perigo da obscuridade na poesia, perigo similar em que, na linha do purismo supostamente clássico, os detratores da poesia barroca acreditavam que esta pudesse cair.

4 V. Schopenhauer, O Mundo como Vontade e Representação. Lisboa: Rés, s/d.

5 Acredito que as discussões pioneiras de M. Pêcheux sobre a consistência epistemológica dos recortes de uma lingüística dita clássica mantêm-se hoje ainda muito fecundas. V. do autor: Analyse Automatique du Discours, Paris: Dunod, 1969 e La Langue Introuvable. Paris: Maspero, 1981 (co-autoria cm F. Gadet).

6 São Paulo: Ed. Perspectiva-EDUSP, 1994.

7 In Transposição in Trevo. São Paulo: Duas Cidades, 1988, p. 33.

8 Idem, p. 31.

9 V. Paris: Seuil, 1973. How to do Things with Words, no original.

10 Essa noção de singularidade aplicada à linguagem me veio à mente quando da leitura do ensaio de Edgar Morin "Le Retour de l'Événement", publicado em Communications. 18 Paris: Seuil, 1972. Com base nela retrabalhei a noção de discurso no ensaio "Sobre a Noção de Discurso" editado em Sobre o Discurso. Série Estudos 6. Uberaba: Fista, 1981. 11 In Helianto. Trevo, p. 131.

12 In Transposição. Trevo, p. 14. 